\title{
Group based prenatal care in a low-and high risk population in the Netherlands: a study protocol for a stepped wedge cluster randomized controlled trial
}

\author{
Birgit S. van Zwicht ${ }^{1 *}$, Matty R. Crone², Jan M. M. van Lith ${ }^{1}$ and Marlies E. B. Rijnders ${ }^{3}$
}

\begin{abstract}
Background: CenteringPregnancy (CP) is a multifaceted group based care-model integrated in routine prenatal care, combining health assessment, education, and support. CP has shown some positive results on perinatal outcomes. However, the effects are less obvious when limited to the results of randomized controlled trials: as there are few trials and there is a variation in reported outcomes. Furthermore, former research was mostly conducted in the United States of America and in specific (often high risk) populations. Our study aims to evaluate the effects of CP in the Netherlands in a general population of pregnant women (low and high risk). Furthermore we aim to explore the mechanisms leading to the eventual effects by measuring potential mediating factors.
\end{abstract}

Design: We will perform a stepped wedge cluster randomized controlled trial, in a Western region in the Netherlands. Inclusion criteria are <24 weeks of gestation and able to communicate in Dutch (with assistance). Women in the control period will receive individual care, women in the intervention period (starting at the randomized time-point) will be offered the choice between individual care or CP. Primary outcomes are maternal and neonatal morbidity, retrieved from a national routine database. Secondary outcomes are health behavior, psychosocial outcomes, satisfaction, health care utilization and process outcomes, collected through selfadministered questionnaires, group-evaluations and individual interviews. We will conduct intention-to-treat analyses. Also a per protocol analysis will be performed comparing the three subgroups: control group, CP-participants and non-CP-participants, using multilevel techniques to account for clustering effects.

Discussion: This study contributes to the evidence regarding the effect of $\mathrm{CP}$ and gives a first indication of the effect and implementation of CP in both low and high-risk pregnancies in a high-income Western society other than the USA. Also, measuring factors that are hypothesized to mediate the effect of CP will enable to explain the mechanisms that lead to effects on maternal and neonatal outcomes.

Trial registration: Dutch Trial Register, NTR4178, registered September $17^{\text {th }} 2013$.

Keywords: Group Prenatal Care, Group Care, Pregnancy Outcome, Health Behavior, Patient Satisfaction, Prenatal care/methods, Infant, Newborn, Group Processes, Patient Education, CenteringPregnancy

\footnotetext{
* Correspondence: b.s.van_zwicht@lumc.nl

1 Department of Obstetrics, Leiden University Medical Center, PO Box 9600,

2300 RC, Leiden, The Netherlands

Full list of author information is available at the end of the article
} 


\section{Background}

In the Netherlands, perinatal mortality and morbidity is relatively high compared to other European countries. One in six children is born with health problems, defined as congenital anomalies, preterm birth, low birth weight and a low Apgar score [1]. Risk factors for adverse perinatal outcomes are amongst others life style (e.g. in the Netherlands $11 \%$ of the women with a lower education level smoke during pregnancy [2]), psychological issues [3], work related risks [4], medication use [5] and chronic illnesses [6]. In addition, perinatal outcomes are worse for ethnic minorities (non-Western ethnicity) $[7,8]$ and for Western women living in deprived urban areas $[9,10]$. Influencing these risk factors could lower the perinatal morbidity rate. Often, however, interventions targeted at the general population do not reach (ethnic) minorities and have limited effects on health behavior [11-13].

In 2012, CenteringPregnancy (CP) was introduced in the Netherlands [14]. CP, developed in the United States of America (USA), is a model of prenatal group based care, within which one-to-one visits are being replaced by group consultations [15]. CP combines the three major components of care - health assessment, education, and support. The group based character of CP allows more time for self-management, education, skill building, and caregiver-patient interaction [16-18]. In addition, the group process can strengthen patient's self-efficacy by vicarious learning and modeling by seeing others successfully overcoming barriers and accomplishing desired behavioral changes [19-22]. Next, CP is integrated in the Dutch routine prenatal care, which is freely accessible to all women in the Netherlands (in 2014 173,544 women received prenatal care [23]). The integrated character improves the reach of the preventive activities that are embedded in CP, as was shown by a former Dutch study concluding that women from an ethnic minority group evaluated a prevention program that was fully integrated in routine midwifery care as highly acceptable and satisfactory [24]. In summary, CP has the potential to effectively influence the risk factors for adverse perinatal outcomes to reach high-risk groups.

Research on CP has shown some positive effects: amongst others on health literacy $[25,26]$, preparedness for labor and birth [17], and initiating breastfeeding [17, 27]. Women reported receiving more social support [28, 29], and were more satisfied with provided care [17, 28-30]. Moreover, the number of preterm births significantly decreased in a high-risk population, the mean birth weight increased and the number of women who received substandard care was reduced [17, 29].

However, a part of the evidence is derived from nonrandomized studies. The evidence from randomized controlled trials (RCT) is less obvious, which is due to the limited number of RCT's on prenatal group-based care and the variation in the reported outcomes [17, 27, 30, 31]. Recently, Caitlin et al. concluded that additional research is required to assess the effects of prenatal group-based care models, such as $\mathrm{CP}$, on neonatal and maternal outcomes [26]. Furthermore, most results of the effect of CP originate from experimental studies conducted in high-risk populations and in the USA $[17,29,31-34]$. It is unknown what the effect of $\mathrm{CP}$ is in a different maternity healthcare system and in the general population.

The aim of the present study is to evaluate the effects of CP in the Netherlands in primary health care (low risk population) as well as in hospital based care (moderate to high risk population) on neonatal and maternal health outcomes, health behaviors and psychosocial outcomes. The effectiveness of $\mathrm{CP}$ will be established by comparing the outcomes in the intervention group (prenatal care within the $\mathrm{CP}$ model) and the control group (usual individual care). Primary hypotheses are that in comparison to the control group, the intervention condition will lead to better neonatal and maternal outcomes. Secondary hypotheses are that the effect on the outcome variables is mediated by (changes in) health literacy, self-regulation, health behavior, health care utilization as well as level of group cohesion and level of implementation.

\section{Methods \\ Design}

This study will be performed in thirteen midwifery practices (primary care, low-risk population) and two hospitals (secondary care, moderate to high-risk population) that do not yet offer CenteringPregnancy within the region 'northern South-Holland' (an urban - suburban setting). A stepped wedge cluster randomized controlled trial design is chosen for several reasons. Firstly, randomization at individual level is not appropriate, as training professionals in $\mathrm{CP}$ will most probably also affect the non-CP consultations. Secondly, since midwifery care in the Netherlands is subjected to marketing forces, cluster randomization is expected to result in unfair competition between independent centers operating in the same region. Within the chosen design, all clusters (midwifery practice or hospital) start to collect control data at the same time (control period). Clusters will subsequently implement the intervention at a different, randomly selected time point and will then start to collect intervention data (intervention period). For this study, we will divide all fifteen centers into three groups and will randomly assign each group to one of three time points (steps) at which they will start to implement the intervention, with a between-step period of 3 months. 


\section{Data collection}

All women that register for prenatal care at a participating center will receive written information about the study. All women under 24 weeks of gestational age (GA) at inclusion who are able to communicate in Dutch (with assistance) will be asked to participate in the study. Their care provider will verbally inform the women at their first prenatal consultation (generally around 8-12 weeks of GA) and will ask them for informed consent. No exclusion criteria will be employed. Participation includes permission to collect women's routine pregnancy outcomes as registered in the National Dutch Perinatal Data Registry (Perined, see end of this section) and optional agreement to fill out four self-administered questionnaires. For participants under the age of 18 , informed consent of their parents or caregivers will be obtained.

\section{Control group}

Within the control period, all participants will be part of the control group and will receive usual individual prenatal care. See Fig. 1.

\section{Intervention group}

Within the intervention period, pregnant women are offered perinatal care in the CP model. In the CP model traditional prenatal care with one-to-one visits with a perinatal care provider is replaced by the use of a group model [35]. Care is provided by a midwife or an obstetrician (facilitator) and a co-facilitator to groups of eight to twelve women of similar gestational age. Groups meet eight to ten times during pregnancy at the usual scheduled visits, with sessions running for 90 to $120 \mathrm{~min}$. The usual prenatal health assessment is integrated with information, education and peer support. All involved care providers will be trained by licensed trainers to perform $\mathrm{CP}$. The intervention period begins when the center starts to recruit for their first CP group, after the randomized time point. All women included in the study during this period will be part of the intervention group. In addition to the study information, participants will be informed about $\mathrm{CP}$ at their first prenatal consultation and will be given the choice to participate in CP. Women that do not participate in $\mathrm{CP}$ will receive usual individual care, resulting in two sub-groups within the intervention group. See Fig. 1.

We will use data from the Perined database. The Perined database contains linked and validated routine care information concerning pregnancy, delivery, (re)admissions and pregnancy outcomes [36]. Data are routinely and separately registered by midwives, obstetricians, general practitioners and paediatricians/neonatologists. For this study, the Perined data will be complemented with data from the questionnaires to be completed by participating women at four time points: Table 1 provides

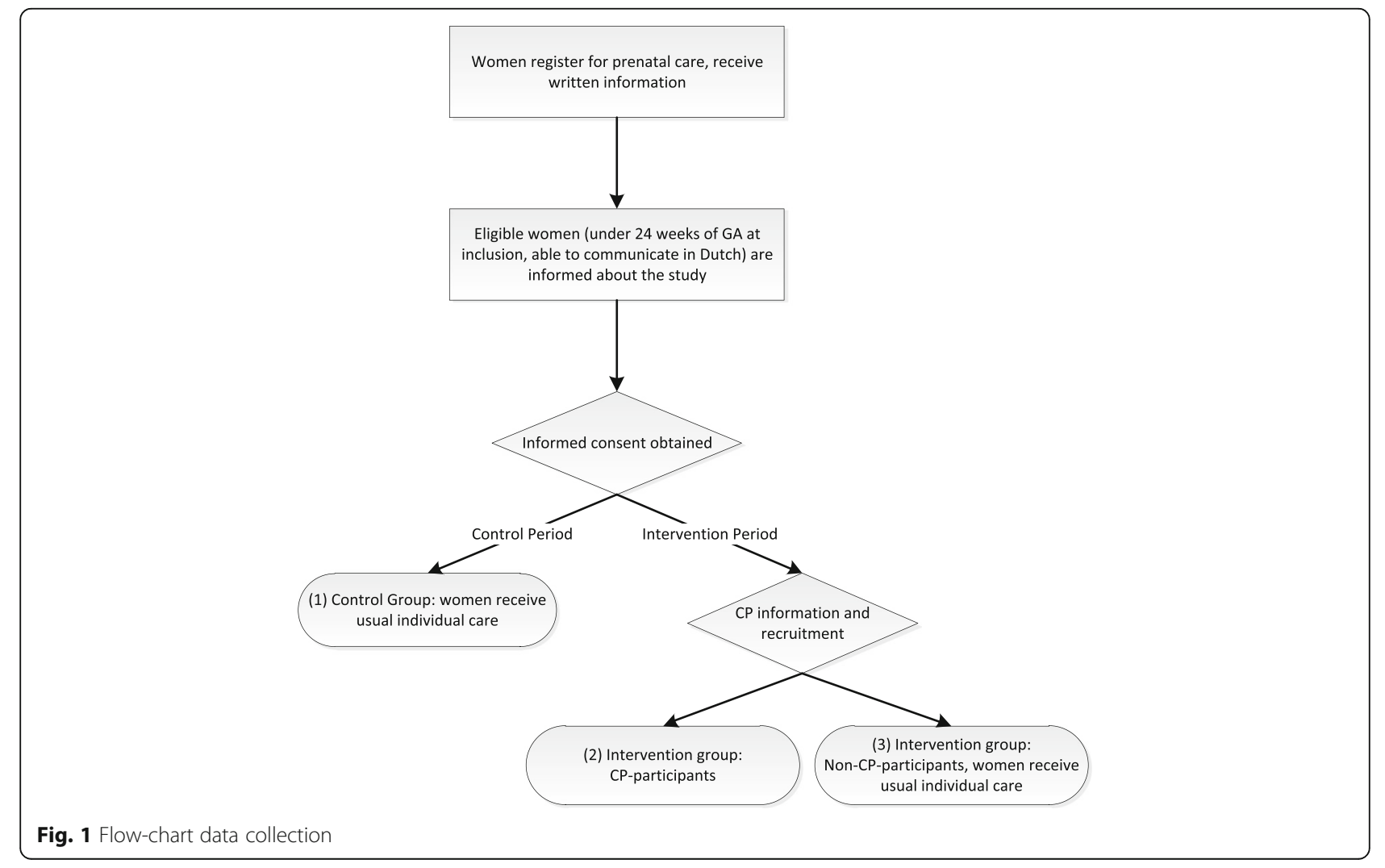


Table 1 Overview of items in the questionnaires at four measurement time points

\begin{tabular}{|c|c|c|c|}
\hline $\begin{array}{l}\text { T1, inclusion } \\
(8-12 \text { weeks of } G A)\end{array}$ & $\begin{array}{l}\text { T2 } \\
(28 \text { weeks of } G A)\end{array}$ & $\begin{array}{l}\text { T3 } \\
\text { (36 weeks of GA) }\end{array}$ & $\begin{array}{l}\text { T4 } \\
\text { (6 weeks postpartum) }\end{array}$ \\
\hline Basic characteristics, current weight & Life style Knowledge (2) & Life style (3), medication use (2) & $\begin{array}{l}\text { Life style (4), prenatal and } \\
\text { perinatal health care use (2) }\end{array}$ \\
\hline Life style and medication use & Life style (2) & Prenatal health care use & $\begin{array}{l}\text { Labor experience, and } \\
\text { emotions during labor }\end{array}$ \\
\hline Preconceptional health care use & Depression & Prenatal Care Knowledge (2) & $\begin{array}{l}\text { Breastfeeding initiation and } \\
\text { duration }\end{array}$ \\
\hline Life style- and Prenatal care Knowledge & $\begin{array}{l}\text { Participation and experience } \\
\text { of } C P^{\mathrm{a}}\end{array}$ & Stress and Coping (2) & $\begin{array}{l}\text { Neonatal sleeping- and } \\
\text { crying behavior }\end{array}$ \\
\hline Stress and Coping & & Social Support (2) & Self-efficacy in child care \\
\hline Social Support & & Readiness for Labor and Baby care & Depression (2) \\
\hline Intended pregnancy education & & $\begin{array}{l}\text { Expectations on labor and child } \\
\text { birth, intentions on infant feeding }\end{array}$ & Pregnancy education (2) \\
\hline \multirow[t]{2}{*}{ Intended participation $\mathrm{CP}^{\mathrm{a}}$} & & Prenatal Care Satisfaction & Participation CP (3) ${ }^{a}$ \\
\hline & & $\begin{array}{l}\text { Participation and experience of } \\
C P(2)^{\mathrm{a}}\end{array}$ & \\
\hline
\end{tabular}

${ }^{a}$ Complementary items for intervention group

an overview of the timing of the different items. Reminders will be sent after 1, 2 and 3 weeks and participants will be reminded by their care provider. Finally, we will use implementation data from CP-group-evaluations and qualitative data from semi-structured interviews with care providers. Outcome measurements are described below. More details on instruments used in the questionnaires are provided in Table 2.

\section{Outcomes}

\section{Basic characteristics}

The basic characteristics that will be collected are age, (parental) country of birth, religion, educational level, marital status, employment status, and parity.

\section{Neonatal health outcomes}

The primary neonatal outcomes are perinatal mortality (defined as death per 1000 still- and life births from a GA above 22 weeks to 7 days postpartum) and perinatal morbidity. Perinatal morbidity (composite outcome) is defined as presence of congenital abnormalities, small for gestational age (birth weight below $10^{\text {th }}$ percentile), preterm birth ( $<37$ weeks of GA), Apgar score after $5 \mathrm{~min}<7$ and/or admission to a neonatal intensive-care unit (immediately after birth). These outcomes will be retrieved from the Perined database, as well as gestational age at birth and birth weight. Other neonatal outcomes that will be addressed in the self-administered questionnaires are child's crying- and sleeping behavior per $24 \mathrm{~h}$ (and to what extent women's expectations on crying behavior are met), consultations with a general practitioner and/or pediatrician and admission to the hospital within 6 weeks postpartum.

\section{Maternal health outcomes}

We will collect data on maternal mortality and morbidity (defined as intensive care admission, eclampsia/HELLP, and/or postpartum hemorrhage $\geq 1000 \mathrm{ml}$ ), and prenatal and perinatal referrals to specialized obstetrical care.

\section{Labor and birth outcomes}

Birth outcomes that will be collected are: intended and actual place of delivery, type of delivery (spontaneous or induced), mode of delivery (non-operative vaginal delivery, operative vaginal delivery, and planned and unplanned cesarean section), augmentation (yes/no), and need for analgesia (epidural, remifentanil, pethidine). These outcomes will be retrieved from the Perined database and complemented by data from the questionnaires regarding expectations on labor pain, intentional use of analgesia, perceived duration of delivery (Table 1). We will measure women's readiness for labor using an item designed by Ickovics et al. [17]. Women's delivery experience will be measured with the Labor and Delivery Index (LADY-X) [37] and women's sense of control during delivery with the Labour Agentry Scale (LAS-10) [38].

\section{Health behavior outcomes and health literacy}

Health behavior outcomes and health literacy will be collected using the questionnaires. Health behavior outcomes are: physical activity (number of 30-min exercise per week and self-judgment physical activity), nutritious behavior (breakfast-, vegetable-, fruit-, juice- and snackconsumption, and self-judgment eating behavior), substance use (tobacco-, alcohol-, and soft or hard drug consumption, and intentions towards smoking cessation), medication use (folic acid use and use of (prescribed) drugs), intention of infant feeding and attitude 
Table 2 Overview of instruments that will be used in the study

\begin{tabular}{|c|c|c|c|c|c|}
\hline Tool & Constructs & Items & Scale — Analysis & Validation & References \\
\hline \multicolumn{6}{|l|}{ Labor and birth outcomes } \\
\hline Readiness for labor-item & $\begin{array}{l}\text { On a scale of } 0 \text { to } 100 \text {, where } \\
0 \text { is not at all and } 100 \text { is } \\
\text { completely, how ready do } \\
\text { you feel for labor and } \\
\text { delivery? }\end{array}$ & 1 item & 0-100 - total score & Not available & Ickovics et al., 2007 [17] \\
\hline $\begin{array}{l}\text { Labor and Delivery Index } \\
(\text { LADY-X) }\end{array}$ & $\begin{array}{l}\text { Quality of received care and } \\
\text { maternal emotions }\end{array}$ & $\begin{array}{l}7 \text { items: e.g. "Information } \\
\text { given by the healthcare } \\
\text { professionals during } \\
\text { childbirth." }\end{array}$ & $\begin{array}{l}3 \text { point scale }{ }^{a}-\text { sum score } \\
\text { (range 0-14) }\end{array}$ & $\begin{array}{l}\text { Test-retest reliability, } \\
\mid C C^{\mathrm{b}}>.80 ; \\
\text { Convergent and divergent } \\
\text { validity } r=.24-61 ; \\
\text { Construct validity } p<.001-.02 \text {. }\end{array}$ & Gärtner et al., 2015 [37] \\
\hline $\begin{array}{l}\text { Shortened Labor Agentry } \\
\text { Scale (LAS-10) }\end{array}$ & $\begin{array}{l}\text { Sense of control during } \\
\text { childbirth }\end{array}$ & 10 items: e.g."I felt confident." & $\begin{array}{l}7 \text { point scale (almost always- } \\
\text { rarely) - sum score (range } \\
\text { 10-70) }\end{array}$ & $\mathrm{A}^{\mathrm{c}}=.85-.97^{\mathrm{d}}$ & $\begin{array}{l}\text { Hodnett and Simons-Tropea, } \\
1987 \text { [38] } \\
\text { Geerts et al., } 2014 \text { [59] }\end{array}$ \\
\hline \multicolumn{6}{|l|}{ Health literacy } \\
\hline $\begin{array}{l}\text { Prenatal/Postnatal care } \\
\text { knowledge }\end{array}$ & $\begin{array}{l}\text { Prenatal and postnatal care } \\
\text { knowledge }\end{array}$ & $\begin{array}{l}19 \text { items: e.g." Babies of } \\
\text { mothers who smoke tend to } \\
\text { be smaller than babies of } \\
\text { mothers who do not smoke." }\end{array}$ & $\begin{array}{l}5 \text { point scale (definitely false- } \\
\text { definitely true) - sum score } \\
\text { (range 0-95) }\end{array}$ & $a=.65$ & Ickovics et al., 2007 [17] \\
\hline \multicolumn{6}{|l|}{ Psychosocial outcomes } \\
\hline $\begin{array}{l}\text { Revised Prenatal Distress } \\
\text { Questionnaire (NuPDQ) }\end{array}$ & $\begin{array}{l}\text { Concerns about birth/baby, } \\
\text { concerns about weight/body } \\
\text { image, concerns about } \\
\text { emotions/relations }\end{array}$ & $\begin{array}{l}\text { 9-17 items: e.g. "Are you } \\
\text { feeling bothered, worried or } \\
\text { upset at this point in your } \\
\text { pregnancy about taking care } \\
\text { of a new born baby?" }\end{array}$ & $\begin{array}{l}3 \text { point scale (not at all-very } \\
\text { much) - sum score (range } \\
0-34 \text { ) }\end{array}$ & $\begin{array}{l}\text { Test-retest reliability } r=.75 \text {, } \\
a=.80-.81^{d}\end{array}$ & $\begin{array}{l}\text { Yali and Lobel, } 1999 \text { [39] } \\
\text { Yali and Lobel, } 2002 \text { [40] } \\
\text { Alderlice et al., } 2012 \text { [41] }\end{array}$ \\
\hline $\begin{array}{l}\text { Cambridge Worry Scale } \\
\text { (CWS) }\end{array}$ & $\begin{array}{l}\text { Women's major worries in } \\
\text { pregnancy: socio-medical, } \\
\text { health, socio-economic, and } \\
\text { relational }\end{array}$ & $\begin{array}{l}17 \text { items: e.g. "How much of } \\
\text { a worry is your housing to } \\
\text { you?" }\end{array}$ & $\begin{array}{l}6 \text { point scale (not a worry- } \\
\text { major worry) - at item level } \\
\text { or using total (range 0-85) or } \\
\text { factor scores }\end{array}$ & $\begin{array}{l}\text { Socio-medical } a=.71 ; \text { Health } \\
a=.70 ; \text { Socio-economic } a \\
=.29-63 ; \text { Relational } a=.67 . \\
\text { Test-retest reliability } \\
r=.69-.72\end{array}$ & $\begin{array}{l}\text { Green and Kafetsios, } \\
1997 \text { [42] } \\
\text { Green et al., } 2003 \text { [47] }\end{array}$ \\
\hline $\begin{array}{l}\text { Coping (based on the } \\
\text { Revised Prenatal Coping } \\
\text { Inventory) }\end{array}$ & $\begin{array}{l}\text { Problem focused active } \\
\text { coping, emotion focused } \\
\text { active coping, emotional } \\
\text { passive coping }\end{array}$ & $\begin{array}{l}9 \text { items: e.g. "How often did } \\
\text { you try not to think about it?" }\end{array}$ & $\begin{array}{l}5 \text { point scale (never-very } \\
\text { often) - sum score per } \\
\text { subscale (range } 0-12 \text { ) }\end{array}$ & Not available & $\begin{array}{l}\text { De Ridder et al., } 1996 \text { [48] } \\
\text { De Ridder et al., } 1998 \text { [49] } \\
\text { Savelkoul et al., } 2000 \text { [50] } \\
\text { Hamilton and Lobel., 2008 } \\
\text { [51] }\end{array}$ \\
\hline $\begin{array}{l}\text { Social Support List-12 Inter- } \\
\text { action (SSL-12 I) }\end{array}$ & $\begin{array}{l}\text { Daily support, problem } \\
\text { support and appreciation } \\
\text { support }\end{array}$ & $\begin{array}{l}12 \text { items: e.g. "Do you get } \\
\text { invited to a party or dinner } \\
\text { sometimes?" }\end{array}$ & $\begin{array}{l}4 \text { point scale (seldom-very } \\
\text { often) - scale scores (range } \\
4-16) \text { and sum score (range } \\
12-48 \text { ) }\end{array}$ & $\begin{array}{l}\text { Daily support } \mathrm{a}=.70-.80^{\mathrm{d}} ; \\
\text { Problem support } \mathrm{a}=.72-.89^{\mathrm{d}} \\
\text { Appreciation support } \\
\mathrm{a}=.72-.82^{\mathrm{d}} .\end{array}$ & $\begin{array}{l}\text { Kempen et al., } 1995 \text { [60] } \\
\text { Bridges et al., } 2002 \text { [53] } \\
\text { Van Sonderen., } 2012 \text { [52] }\end{array}$ \\
\hline
\end{tabular}


Table 2 Overview of instruments that will be used in the study (Continued)

\begin{tabular}{|c|c|c|c|c|c|}
\hline $\begin{array}{l}\text { Edinburgh Postnatal } \\
\text { Depression Scale (EPDS) }\end{array}$ & $\begin{array}{l}\text { Prenatal and postnatal } \\
\text { depression } \\
\text { The EPDS was originally } \\
\text { developed for postnatal use, } \\
\text { but was validated as a } \\
\text { prenatal screening } \\
\text { instrument. }\end{array}$ & $\begin{array}{l}10 \text { items: e.g. "I have been } \\
\text { able to laugh and see the } \\
\text { funny side of things." }\end{array}$ & $\begin{array}{l}4 \text { point scale }{ }^{a}-\text { sum score } \\
\text { (range } 0-30 \text { ) }\end{array}$ & $a=.80$ & $\begin{array}{l}\text { Cox et al., } 1987[54] \\
\text { Murray et al., } 1990[61] \\
\text { Green et al., } 1994 \text { [62] } \\
\text { Adouard et al., } 2004 \text { [63] }\end{array}$ \\
\hline \multicolumn{6}{|l|}{ Parenting outcomes } \\
\hline $\begin{array}{l}\text { Readiness for baby } \\
\text { care-item }\end{array}$ & $\begin{array}{l}\text { "On a scale of } 0 \text { to } 100 \text {, } \\
\text { where } 0 \text { is not at all and } 100 \\
\text { is completely, how ready do } \\
\text { you feel for taking care of } \\
\text { your baby?" }\end{array}$ & 1 item & 0-100 - total score & Not available & Ickovics et al., 2007 [17] \\
\hline $\begin{array}{l}\text { Parental Expectations } \\
\text { Survey (PES) }\end{array}$ & $\begin{array}{l}\text { Women's self-efficacy in child } \\
\text { care }\end{array}$ & $\begin{array}{l}25 \text { items: e.g. "I can manage } \\
\text { the feeding of my baby." }\end{array}$ & $\begin{array}{l}10 \text { point scale (cannot do- } \\
\text { certain can do) - sum score } \\
\text { (range } 25-250 \text { ) }\end{array}$ & $a=.86-.91^{d}$ & $\begin{array}{l}\text { Reece et al., } 1992 \text { [55] } \\
\text { Reece et al., } 1998 \text { [64] } \\
\text { McCarter-Spaulding et al., } \\
2001 \text { [65] }\end{array}$ \\
\hline \multicolumn{6}{|l|}{ Satisfaction with prenatal care } \\
\hline $\begin{array}{l}\text { Patient Participation and } \\
\text { Satisfaction Questionnaire } \\
\text { (PPSQ) }\end{array}$ & $\begin{array}{l}\text { Participation in prenatal care } \\
\text { and satisfaction }\end{array}$ & $\begin{array}{l}22 \text { items: e.g. "Helpful } \\
\text { information was given to me } \\
\text { about my pregnancy." }\end{array}$ & $\begin{array}{l}5 \text { point scale (not applicable } \\
\text { and very dissatisfied-very sat- } \\
\text { isfied) - scale scores and total } \\
\text { sum score (range 22-110) }\end{array}$ & $\begin{array}{l}\text { Participation } a=.93 ; \\
\text { Satisfaction } a=.93 \\
\text { Total } a=.95 .\end{array}$ & $\begin{array}{l}\text { Littlefield et al., } 1987 \text { [56] } \\
\text { Ickovics et al., } 2007 \text { [17] }\end{array}$ \\
\hline
\end{tabular}


towards breastfeeding, and infant feeding on day one, at 1 week postpartum and at 6 weeks postpartum. Women's prenatal and postnatal care knowledge will be measured with a scale developed by Ickovics et al. [17].

\section{Psychosocial outcomes}

Psychosocial outcomes include perceived stress, coping, social support, and depression. Stress will be measured using the Prenatal Distress Questionnaire (NuPDQ), which is a revised version of the original 12-item scale developed by Yali and Lobel in 1999 [39-41]. Socio-economic and relational stress will be measured by four items of the Cambridge Worry Scale (CWS), complementing the NuPDQ [42-47]. We have added a concluding item on the amount of experienced stress on a scale from 0.0 to 10.0. To measure coping we will use a self-developed short instrument measuring three constructs based on the coping strategies as described by De Ridder \& Schreurs (1994), and Savelkoul et al. (2000): problem focused active coping, emotion focused active coping and emotional passive coping [48-50]. Each coping strategy is measured on a subscale and contains three items, which are based on the items of the revised Prenatal Coping Inventory ( $\mathrm{NuPCI})$, using the same answering scale (5 point Likert like scale, $0=$ never tot $4=$ very often) [51]. For example: "How often did you take a walk or performed other physical exercise to feel better?" (emotion focused active coping), "How often did you try not to think about it?" (emotional passive coping), and "How often did you talk to others in the same situation?" (problem focused active coping). Social support will be measured using the social support list-12 Interaction [52, 53]. Depression will be measured using the Edinburgh Postnatal Depression Scale (EPDS) [54].

\section{Parenting outcomes}

We will measure women's readiness for baby care using an item designed by Ickovics et al. [17]. Women's selfefficacy in child care will be evaluated using the Parental Expectations Survey (PES) [55].

\section{Satisfaction with prenatal care}

Women's experience and satisfaction with prenatal care will be evaluated using the Patient Participation and Satisfaction Questionnaire (PPSQ) [56, 57].

\section{Process outcomes}

We will assess the implementation of $\mathrm{CP}$ by monitoring the percentage of women that start $\mathrm{CP}$, the addressed content within the group sessions, the involvement of women and their partners (adherence), and model fidelity. These data will be collected from the CP-groupevaluations, filled out by the group facilitators at the end of each session. These evaluations also contain data on group cohesion. Women's experience with $\mathrm{CP}$ and their inhibiting and facilitating factors to participate will be addressed in the self-administered questionnaires: see Table 1. Inhibiting and facilitating factors in the implementation process and the care providers satisfaction with prenatal care will be addressed in individual semistructured in-depth interviews. Health care utilization of women will be measured in the self-administered questionnaires, addressing preconceptional and prenatal utilization of general health care, and health care utilization provided by a perinatal care center.

\section{Statistical issues \\ Sample size calculation}

A minimal sample of 600 pregnant women in both the intervention and control condition is needed to be able to accept with $95 \%$ confidence and an upper confidence limit less than 1.85, that after the intervention has been implemented, there is at least no significant difference in infant morbidity (using 14\% of infant morbidity as outcome) between $\mathrm{CP}$ and individual care. This sample size is also largely sufficient to find amongst others a difference in prenatal care satisfaction or in proportion of breastfeeding comparable to Ickovics et al, with an $\alpha$ of 0.05 and a power of 0.90 [17]. We will account for a $20 \%$ loss to follow-up and aim to include in total 1600 women (800 in both conditions).

\section{Data analysis}

Data entry will be automatic by using a secured online survey system or (in case of hard copy) scanned and checked using the Teleform software. Data will be stored in a digital data base only accessible to the researchers. Before analysis, all data will be cleaned improving data quality.

We will conduct intention-to-treat analyses to compare the primary and secondary outcomes of the control group with those of the complete intervention group. Also a per protocol analysis will be performed comparing the outcomes of the three subgroups (see Fig. 1): control group (1), CP-participants (2) and non-CP-participants (3). Analyses will be descriptive and inferential (univariate and multivariate), and we plan to perform multilevel techniques to account for the clustering effect among participants in centers and $\mathrm{CP}$-participants in CP-groups. The analysis of the implementation data and health care use will be descriptive. The relation between the degree of implementation and primary and secondary outcomes will be analyzed using multi-level analysis. Furthermore, the interviews with care providers will be conducted using a topic list based on the results of the analysis of the implementation data. They will be transcribed and qualitatively analyzed using a framework approach. 


\section{Discussion}

Former research has shown a positive effect of $\mathrm{CP}$, including a higher birth weight and more prenatal care satisfaction, however the findings were inconsistent $[17,26,27,30,31]$. Furthermore, due to differences in population characteristics and health care system, previous findings cannot be directly extrapolated to the Dutch setting. Our study aims to contribute to the evidence regarding the effect of $\mathrm{CP}$ and will give a first indication of the effect and implementation of CP in a Western highincome society other than the USA. Also, by measuring factors that are hypothesized to mediate the effect of $\mathrm{CP}$, we aim to be able to explain the mechanisms that lead to eventual found effects on maternal and neonatal outcomes.

A strength of our study lies in the stepped wedge cluster design. In this design, participating practices are randomly assigned to the period in which they will start providing CP and will function as their own control group before implementing CP. Also, it allows to take into account time effects. Another strength of the study is the use of routine data to assess several neonatal and maternal outcome measures.

One limitation however is the fact that centers are not yet trained in $\mathrm{CP}$ and that it takes some time to implement, which may lead to less model fidelity and smaller effect sizes. Fidelity to facilitate group processes in CP and content fidelity are known to associate with significant reductions in preterm birth and intensive utilization of care [58]. To gain more insight in the effects of fidelity of the model as provided by health care providers we will collect data on process and implementation, and will relate it to the effects of $\mathrm{CP}$. The possibility of selection bias by letting women choose between $\mathrm{CP}$ or individual care is another limitation of our study. To be able to estimate the degree of selection bias, we will collect numerous demographic and psychosocial data of both groups in the intervention period (CP-participants and Non-CP-participants), also allowing us to correct for differences in basic characteristics. In addition, we will perform an intention-to-treat analysis, as well as a per protocol analysis. Differences in results of both analyses will provide an indication of assumed selection bias.

Abovementioned limitations of the study are at the same time the strengths of our study, since our chosen design and methods are pragmatic, allowing us to evaluate the effect of CP when implemented in daily practice.

\footnotetext{
Abbreviations

(Nu)PDQ: Prenatal Distress Questionnaire; CP: CenteringPregnancy; CWS: Cambridge Worry Scale; EPDS: Edinburgh Postnatal Depression Scale; GA: Gestational Age; LADY-X: Labor and Delivery Index; LAS: Labour Agentry Scale; NuPCl: Prenatal Coping Inventory; PES: Parental Expectations Survey; PPSQ: Patient Participation and Satisfaction Questionnaire; RCT: Randomized Controlled Trial; SCL-90: Sympton Checklist-90; SSL-I 12: support list-12 Interaction; STAI: State-Trait Anxiety Inventory; USA: United States of America
}

\section{Acknowledgements}

Not applicable.

\section{Funding}

This study received funding from ZonMW (the Netherlands Organisation for Health Research and Development (ZonMW) in the context of the research program Pregnancy and Childbirth, grant number 50-50200-98-052. ZonMW peer-reviewed the study protocol before assigning the grant and requests a yearly progress report. They have no role in the interpretation of data or writing manuscripts.

\section{Availability of data and materials \\ Not applicable.}

\section{Authors' contributions}

$M C, M R$, JVL were involved in conception and design of the study. BVZ, MC and MR drafted the manuscript. All listed authors are members of the CONNECT-IN study team, discussing two weekly the progress of the study. All authors participated in the revision of this article. All authors read and approved the final manuscript.

\section{Competing interests}

The authors declare that they have no competing interests.

\section{Consent for publication}

Not applicable.

\section{Ethics approval and consent to participate}

This study has been approved by the Commission of Medical Ethics of the Leiden University Medical Centre (NL44319.058.13). The trial was registered at the Dutch Trial Register (Nederlands Trial Register): NTR4178 (September $17^{\text {th }}$ 2013). All collected data will be made anonymous, and handled confidentially. Data will be exclusively used for this study and key coded stored, according to the standards of use of data in scientific research (Dutch Personal Data Protection Act). Any serious adverse event will be reported to the Commission of Medical Ethics. No data monitoring committee is considered to be needed, since all study participants will receive usual care, in an individual or group setting. Amendments to the study and the end of the study will be notified to the Commission of Medical Ethics. Study results will be offered for publication to international and national journals in the field of obstetrics/gynaecology and implementation research. Furthermore, the results will be presented at national and international congresses.

\section{Author details}

${ }^{1}$ Department of Obstetrics, Leiden University Medical Center, PO Box 9600, 2300 RC, Leiden, The Netherlands. ${ }^{2}$ Department of Public Health and Primary Care, PO Box 9600, 2300 RC, Leiden, The Netherlands. ${ }^{3}$ Department of Child Health TNO, PO Box 22152301 CE, Leiden, The Netherlands.

Received: 30 May 2016 Accepted: 8 November 2016

Published online: 15 November 2016

\section{References}

1. Bonsel G, Birnie E, Denktas S, Poeran J, Steegers EAP. Lijnen in de Perinatale Sterfte, Signalementstudie Zwangerschap en Geboorte 2010..Erasmus MC. 2010. http://www.zonmw.nl/nl/publicaties/detail/lijnen-in-de-perinatalesterfte-signalementstudie-zwangerschap-en-geboorte-2010-1/. Accessed 26 May 2015.

2. Lanting $C$, van Wouwe JP, van den Burg I, Segaar D, van der Pal-de Bruin KM. Smoking during pregnancy: trends between 2001 and 2010. Ned Tijdschr Geneeskd. 2012;156:A5092.

3. Henrichs J, Schenk J, Roza S, Van den Berg M, Schmidt H, Steegers E, et al. Maternal psychological distress and fetal growth trajectories: the Generation R Study. Psychol Med. 2010;40:633-43.

4. Mozurkewich EL, Luke B, Avni M, Wolf FM. Working conditions and adverse pregnancy outcome: a meta-analysis. Obstet Gynecol. 2000;95:623-35.

5. Meyboom-de Jong B, de Jong-van den Berg LT. Pregnancy and drug use. Ned Tijdschr Geneeskd. 1992;136:1843-7.

6. Evers IM, de Valk HW, Visser GH. Risk of complications of pregnancy in women with type 1 diabetes: nationwide prospective study in the Netherlands. BMJ (Clinical Research ed). 2004;328:915. 
7. Troe EJ, Bos V, Deerenberg IM, Mackenbach JP, Joung IM. Ethnic differences in total and cause-specific infant mortality in The Netherlands. Paediatr Perinat Epidemiol. 2006;20:140-7.

8. Alderliesten M, Vrijkotte T, Van Der Wal M, Bonsel G. Late start of antenatal care among ethnic minorities in a large cohort of pregnant women. BJOG. 2007;114:1232-9.

9. de Graaf J, Ravelli A, Wildschut H, Denktaş S, Voorham T, Bonsel G, et al. Perinatale uitkomsten in de vier grote steden en de prachtwijken in Nederland. Ned Tijdschr Geneeskd. 2008;152:2734-40

10. Schölmerich VL, Erdem Ö, Borsboom G, Ghorashi H, Groenewegen P, Steegers EA, et al. The association of neighborhood social capital and ethnic (minority) density with pregnancy outcomes in the Netherlands. PLoS One. 2014:9:e95873.

11. Institute of Medicine. Speaking of Health: Assessing Health Communication Strategies for Diverse Populations. Washington, DC: The National Academies Press; 2002.

12. Jepson RG, Harris FM, Platt $S$, Tannahill C. The effectiveness of interventions to change six health behaviours: a review of reviews. BMC Public Health. 2010;10:538.

13. Kreuter MW, Lukwago SN, Bucholtz RD, Clark EM, Sanders-Thompson V. Achieving cultural appropriateness in health promotion programs: targeted and tailored approaches. Health Educ Behav. 2003;30:133-46.

14. Rijnders M, Detmar, SB, Herschderfer, KC. Implementatie van CenteringPregnancy in Nederland 2012-2015. TNO. 2016. https://www.tno. nl/nl/over-tno/nieuws/2016/5/betere-gezondheidsresultaten-zwangerevrouwen-met-groepszorg/. Accessed 26 May 2016.

15. Massey Z, Rising SS, Ickovics J. CenteringPregnancy group prenatal care: promoting relationship-centered care. J Obstet Gynecol Neonatal Nurs. 2006:35:286-94.

16. Lorig KR, Holman HR. Self-management education: history, definition, outcomes, and mechanisms. Ann Behav Med. 2003;26:1-7.

17. Ickovics JR, Kershaw TS, Westdahl C, Magriples U, Massey Z, Reynolds H, et al. Group prenatal care and perinatal outcomes: a randomized controlled trial. Obstet Gynecol. 2007;110:330.

18. Zantinge EM, Seesing FM, Tol FE, Raats CJ, Spreeuwenberg PM, van Dulmen AM. Shared Medical Appointments: experiences of patients and care givers. Ned Tijdschr Geneeskd. 2009;153:A828.

19. Bandura A. The anatomy of stages of change. Am J Health Promot. 1997;12:8-10.

20. Bodenheimer T, Lorig K, Holman H, Grumbach K. Patient self-management of chronic disease in primary care. JAMA. 2002;288:2469-75.

21. Bandura A. Swimming against the mainstream: the early years from chilly tributary to transformative mainstream. Behav Res Ther. 2004;42:613-30.

22. Sol BG, van der Bijl JJ, Banga JD, Visseren FL. Vascular risk management through nurse-led self-management programs. J Vasc Nurs. 2005;23:20-4.

23. Perined. Perinatale zorg in Nederland 2014. Perined. 2015. https://www. perined.nl/producten/publicaties/jaarboeken. Accessed 26 May 2016.

24. Hesselink AE, Harting J. Process evaluation of a multiple risk factor perinatal programme for a hard-to-reach minority group. J Adv Nurs. 2011;67:2026-37.

25. Baldwin KA. Comparison of selected outcomes of CenteringPregnancy versus traditional prenatal care. J Midwifery Womens Health. 2006;51:266-72.

26. Catling CJ, Medley N, Foureur M, Ryan C, Leap N, Teate A, Homer CS. Group versus conventional antenatal care for women. Cochrane Database Syst Rev. 2015;2:Cd007622.

27. Jafari F, Eftekhar H, Fotouhi A, Mohammad K, Hantoushzadeh S. Comparison of maternal and neonatal outcomes of group versus individual prenatal care: a new experience in Iran. Health Care Women Int. 2010;31:571-84.

28. Teate A, Leap N, Rising SS, Homer CS. Women's experiences of group antenatal care in Australia - the CenteringPregnancy Pilot Study. Midwifery. 2011;27:138-45

29. Grady MA, Bloom KC. Pregnancy outcomes of adolescents enrolled in a CenteringPregnancy program. J Midwifery Womens Health. 2004;49:412-20.

30. Kennedy HP, Farrell T, Paden R, Hill S, Jolivet RR, Cooper BA, Rising SS. A randomized clinical trial of group prenatal care in two military settings. Mil Med. 2011;176:1169-77.

31. Ickovics JR, Earnshaw V, Lewis JB, Kershaw TS, Magriples U, Stasko E, et al. Cluster Randomized Controlled Trial of Group Prenatal Care: Perinatal Outcomes Among Adolescents in New York City Health Centers. Am J Public Health. 2016;106(2):359-365.

32. Klima CS. Centering pregnancy: a model for pregnant adolescents. J Midwifery Womens Health. 2003;48:220-5.
33. Trudnak TE, Arboleda E, Kirby RS, Perrin K. Outcomes of Latina women in CenteringPregnancy group prenatal care compared with individual prenatal care. J Midwifery Womens Health. 2013;58:396-403.

34. Robertson B, Aycock DM, Darnell LA. Comparison of centering pregnancy to traditional care in Hispanic mothers. Matern Child Health J. 2009;13:407-14.

35. Rising SS. Centering pregnancy: an interdisciplinary model of empowerment. J Nurse Midwifery. 1998;43:46-54.

36. Perined. https://www.perined.nl/. Accessed 26 May 2016.

37. Gartner FR, de Miranda E, Rijnders ME, Freeman LM, Middeldorp JM, Bloemenkamp KW, et al. Good reliability and validity for a new utility instrument measuring the birth experience, the Labor and Delivery Index. J Clin Epidemiol. 2015;68:1184-94.

38. Hodnett ED, Simmons-Tropea DA. The Labour Agentry Scale: psychometric properties of an instrument measuring control during childbirth. Res Nurs Health. 1987;10:301-10.

39. Yali AM, Lobel M. Coping and distress in pregnancy: An investigation of medically high risk women. J Psychosom Obstet Gynaecol. 1999;20:39-52.

40. Yali AM, Lobel M. Stress-resistance resources and coping in pregnancy. Anxiety Stress Coping. 2002:15:289-309.

41. Alderdice F, Lynn F, Lobel M. A review and psychometric evaluation of pregnancy-specific stress measures. J Psychosom Obstet Gynaecol. 2012;33:62-77.

42. Green JM, Kafetsios K. Positive experiences of early motherhood: Predictive variables from a longitudinal study. J Reprod Infant Psychol. 1997;15:141-57.

43. Green JM, Snowdon C, Statham H. Pregnant women's attitudes to abortion and prenatal screening. J Reprod Infant Psychol. 1993;11:31-9.

44. Green JM, Statham H, Snowdon C. Women's knowledge of prenatal screening tests. 1: Relationships with hospital screening policy and demographic factors. J Reprod Infant Psychol. 1993;11:11-20.

45. Statham $H$, Green JM. The effects of miscarriage and other unsuccessful'pregnancies on feelings early in a subsequent pregnancy. J Reprod Infant Psychol. 1994;12:45-54.

46. Statham H, Green JM, Kafetsios K. Who worries that something might be wrong with the baby? A prospective study of 1072 pregnant women. Birth. 1997;24:223-33.

47. Green JM, Kafetsios K, Statham HE, Snowdon CM. Factor structure, validity and reliability of the Cambridge Worry Scale in a pregnant population. J Health Psychol. 2003:8:753-64.

48. De Ridder D, Schreurs K. Coping, social support and chronic disease: a research agenda. Psychol Health Med. 1996;1:71-82.

49. De Ridder DT, Schreurs KM, Bensing JM. Adaptive Tasks, Coping and Quality of Life of Chronically III Patients The Cases of Parkinson's Disease and Chronic Fatigue Syndrome. J Health Psychol. 1998;3:87-101.

50. Savelkoul M, Post M, De Witte L, Van Den Borne H. Social support, coping and subjective well-being in patients with rheumatic diseases. Patient Educ Couns. 2000;39:205-18.

51. Hamilton JG, Lobel M. Types, patterns, and predictors of coping with stress during pregnancy: Examination of the Revised Prenatal Coping Inventory in a diverse sample. J Psychosom Obstet Gynaecol. 2008;29:97-104.

52. van Sonderen E. Sociale Steun Lijst-Interacties (SSL-I) en Sociale Steun Lijst-Discrepanties (SSL-D). Groningen: Noorderlijk Centrum voor Gezondheidsvraagstukken; 1993.

53. Bridges KR, Sanderman R, van Sonderen E. An English language version of the social support list: preliminary reliability. Psychol Rep. 2002;90:1055-8.

54. Cox JL, Holden JM, Sagovsky R. Detection of postnatal depression. Development of the 10-item Edinburgh Postnatal Depression Scale. Br J Psychiatry. 1987;150:782-6.

55. Reece SM. The Parent Expectations Survey A Measure of Perceived SelfEfficacy. Clin Nurs Res. 1992;1:336-46.

56. Littlefield V, Adams B. Patient participation in alternative perinatal care: impact on satisfaction and health locus of control. Res Nurs Health. 1987;10:139-48.

57. Littlefield VM, Chang A, Adams BN. Participation in alternative care: Relationship to anxiety, depression, and hostility. Res Nurs Health. 1990;13:17-25.

58. Novick G, Reid AE, Lewis J, Kershaw TS, Rising SS, Ickovics JR. Group prenatal care: model fidelity and outcomes. Am J Obstet Gynecol. 2013;209:112. e1-6.

59. Geerts CC, Klomp T, Lagro-Janssen AL, Twisk JW, Van Dillen J, De Jonge A. Birth setting, transfer and maternal sense of control: results from the DELIVER study. BMC Pregnancy Childbirth. 2014:14:1.

60. Kempen G, Van Eijk L. The psychometric properties of the SSL12-I, a short scale for measuring social support in the elderly. Soc Indic Res. 1995;35:303-12. 
61. Murray D, Cox JL. Screening for depression during pregnancy with the Edinburgh Depression Scale (EDDS). J Reprod Infant Psychol. 1990;8:99-107.

62. Green J, Murray D. The use of the Edinburgh Postnatal Depression Scale in research to explore the relationship between antenatal and postnatal dysphoria. Perinatal psychiatry: use and misuse of the Edinburgh postnatal depression scale Gaskell, London. 1994:180-198.

63. Adouard F, Glangeaud-Freudenthal N, Golse B. Validation of the Edinburgh postnatal depression scale (EPDS) in a sample of women with high-risk pregnancies in France. Arch Womens Ment Health. 2005;8:89-95.

64. Reece SM, Harkless G. Self-efficacy, stress, and parental adaptation: Applications to the care of childbearing families. J Fam Nurs. 1998:4:198-215.

65. McCarter-Spaulding DE, Kearney MH. Parenting Self Efficacy and Perception of Insufficient Breast Milk. J Obstet Gynecol Neonatal Nurs. 2001;30:515-22.

Submit your next manuscript to BioMed Central and we will help you at every step:

- We accept pre-submission inquiries

- Our selector tool helps you to find the most relevant journal

- We provide round the clock customer support

- Convenient online submission

- Thorough peer review

- Inclusion in PubMed and all major indexing services

- Maximum visibility for your research

Submit your manuscript at www.biomedcentral.com/submit
Biomed Central 